\title{
Ameloblastoma of the Maxilla : Report of a Case
}

\author{
Yukie Yamamura, Toshio Yoshihara
}

Department of Otolaryngology, School of Medicine, Tokyo Women's Medical University, Tokyo

\begin{abstract}
Ameloblastomas arising in the maxilla are rare, and preoperative diagnosis is often difficult due to its rarity and atypical clinical findings. A 61-year-old man ameloblastoma involving the maxillary antrum and the nasal cavity was seen on January 25, 2002, for 24-month history of slowly increasing left nasal obstruction. He reported severe left nasal obstruction, but had no nasal discharge, postnasal drip, cheek swelling, or dental or vision problems.

Radiography showed a multilobular legion in the left nasal cavity and the left maxillaly antrum with extension to the molar area, which was most remarkable with T2-weighed MRI.

On May 8, we explored the left maxillary sinus via a Caldwell-Luc approach. The tumor occupied the maxillary antrum and extended into the left nasal cavity via the maxillary ostium. The lateral maxillary wall was eroded, but the tumor was not invasive and was removed totally with minimal bleeding. Histologically, the excised tumor was compatible with ameloblastoma, plexiform variant.
\end{abstract}

Key words : ameloblastoma, maxilla, odontogenic tumor

\section{Introduction}

Odontogenic tumors include odontoma, myxoma, ameloblastoma, and peripheral cementifying dysplasia. Of these, the most commonly occurring is odontoma and the rarest ameloblastoma. Ameloblastomas frequently arise in the mandible but not the maxilla. Their rarity and atypical clinical features often make preoperative diagnosis in the maxilla difficult. We report a case of ameloblastoma involving the maxillary sinus and nasal cavity.

\section{Case report}

A 61-year-old man referred on January 25, 2002, for a 24-month history of slowly progressing nasal obstruction was diagnosed with chronic left maxillary sinusitis and left nasal polyp elsewhere 4 months prior to admission. He was referred for surgery because macrolide antibiotics had not been effective. He reported severe left nasal obstruction, but had no nasal discharge, postnasal drip, cheek swelling, or dental or vision problems.

On examination, anterior rhinoscopy showed a pink polypoid mass in the left nasal cavity (Fig. 1). Coronal computed tomography (CT) showed a soft tissue mass filling the left nasal cavity and left maxillary sinus, destroying the medial wall of the maxilla. The mass extended to the left ethmoid sinus. After the administration of iopamidol, axial CT showed an irregular enhanced lesion in the left maxillary sinus with erosion of the posterior wall (Fig.2 a, b). Coronal T2-weighed magnetic resonance imaging (MRI) showed high signal intensity in the lobular region in the maxillary sinus and left nasal cavity. The left ethmoid sinus showed intermediate signal intensity suggesting fluid collection. Axial T2-weighed MRI showed a region with high signal intensity eroding the left maxillary molar area (Fig. 3 a, b).

Specimens biopsied on February 1 2002, from the polypoid region in the left nasal cavity showed columnar epithelium cells forming ducts, cell nests, or interlacing cords. Stroma consisted of fibrous, mucoid, and chondroid regions. The pathologic diagnosis suggested pleomorphic adenoma, necessitating exploration of the left maxillary sinus on April 30 via a Caldwell-Luc approach. A grayish solid tumor occupied the maxillary sinus, extending into the left nasal cavity and destroying the me- 


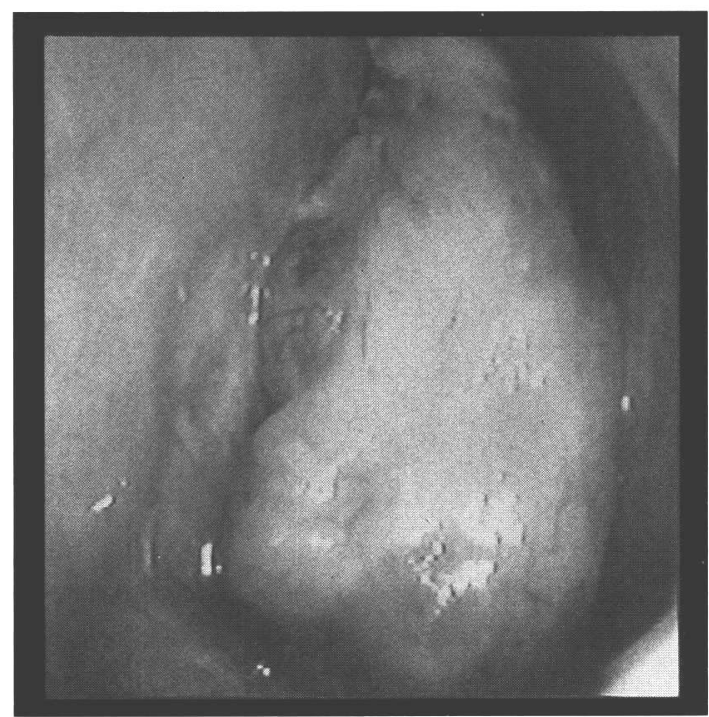

Fig. 1 Anterior rhinoscopy showing a pink polypoid mass in the left nasal cavity.

dial wall of the maxilla. Thick mucous secretion was observed in the ethmoid and sphenoid sinuses. The lateral maxillary wall was eroded but the tumor had not invaded the molar area and could be removed totally with minimal bleeding.

Tumor tissues showed tubular or interdigitating cords of single-layer columnar epithelial cells (Fig. 4) resembling those of the specimen from the nasal cavity. The specimen from the maxillary sinus, however, evidenced typical ameloblastomatous histology such as a microcyst in the epithelial and stromal components and loose, spindle-shaped cells surrounded by columnar epithelial cells.

Immunohistochemically, stellate cells were positive for cytokeratin with KL-1 antibody (Fig. 5), whereas proliferating cell nuclear antigen (PCNA), S-100 protein, and actin showed little immunoreaction. The postoperative course was uneventful, and neither recurrence nor serious complications have occurred to the present.

\section{Discussion}

Ameloblastomas are relatively rare odontogenic tumors constituting 3 to $19 \%$ of all tumors and cysts of the maxilla and mandible ${ }^{1-3)}$. It is reported that $80 \%$ of ameloblastomas occur in the mandible and those arising from the maxillary sinus are rare ${ }^{4,5)}$. Ameloblastomas may occur in any age groups but appear most commonly in the third to fifth decades of life. Reichart ${ }^{5)}$ reported
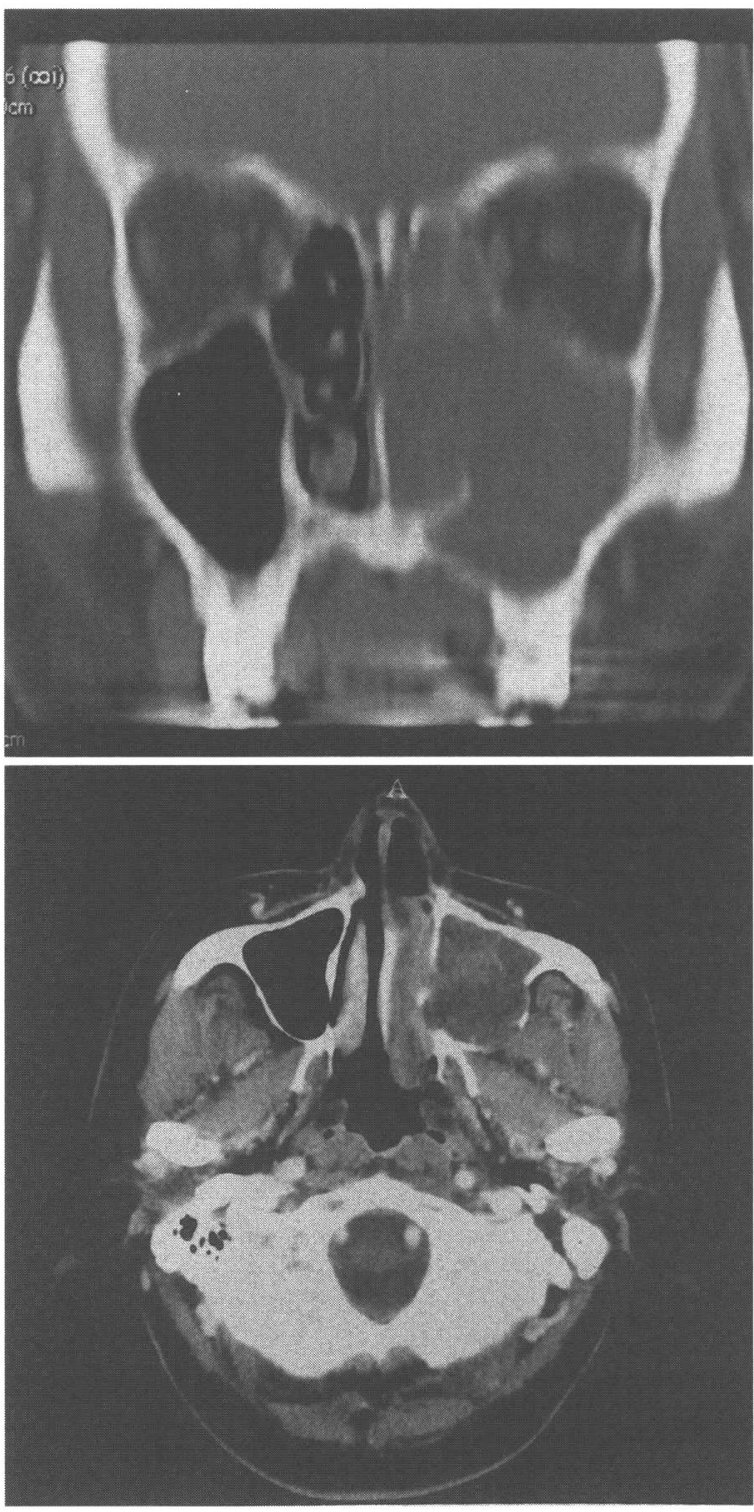

Fig. 2 (a) Coronal computed tomography (CT) showing soft tissue mass in the left nasal cavity and maxillary sinus, destroying the medial wall of the maxilla. The mass also extended to the left ethmoid sinus without bony destruction.

(b) Axial CT scan, after the administration of iopamidol, showing irregular enhanced lesion in the left maxillary sinus with erosion on the posterior wall.

that patients with maxillary ameloblastomas are older than those with mandible ameloblastomas, averaging 47.0 years compared to mandibular patients, whose average age was 35.2 years. Gender distribution was similar.

Radiographic findings in our case suggest that the primary region of the tumor was the molar area, generally considered the main localization of maxillary ameloblas- 

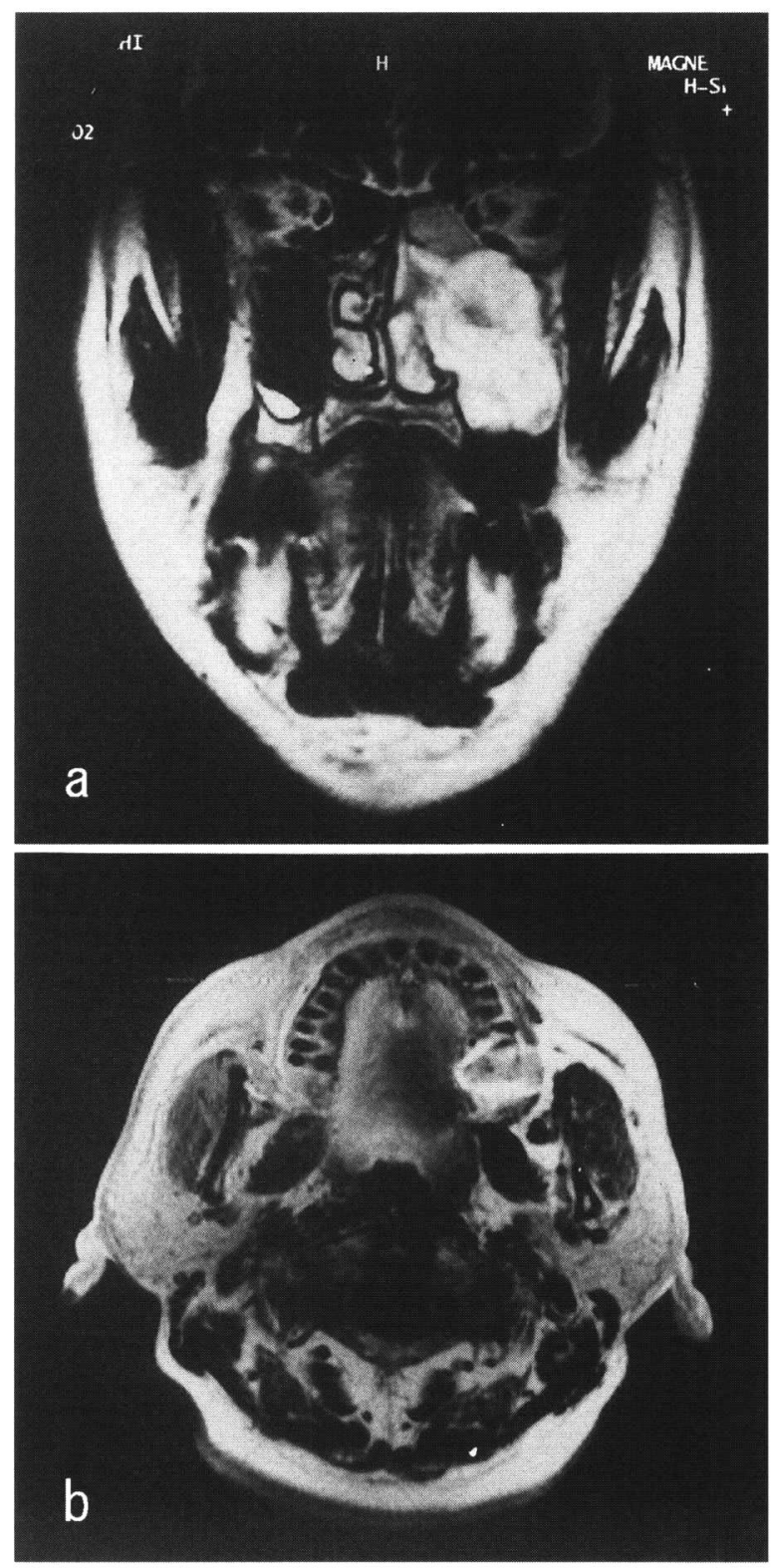

Fig. 3 (a) Coronal T2-weighed MRI showing a lobular high signaled region in the maxillary sinus and the left nasal cavity. The left ethmoid sinus was filled with intermediate signal region suggesting fluid correction.

(b) Axial T2-weighed MRI showing a high signaled region extended to the left maxillal molar area.

tomas $^{5}$. The most common clinical symptom of ameloblastomas in the maxilla is swelling of the gingiva, buccal, or hard palate, but our patient reported only nasal obstruction, probably because the tumor was localized in the maxillary sinus and mainly extended to the nasal cavity.

Ameloblastoma appearance in CT or MR is not definitive and it is difficult to differentially diagnose these tu-

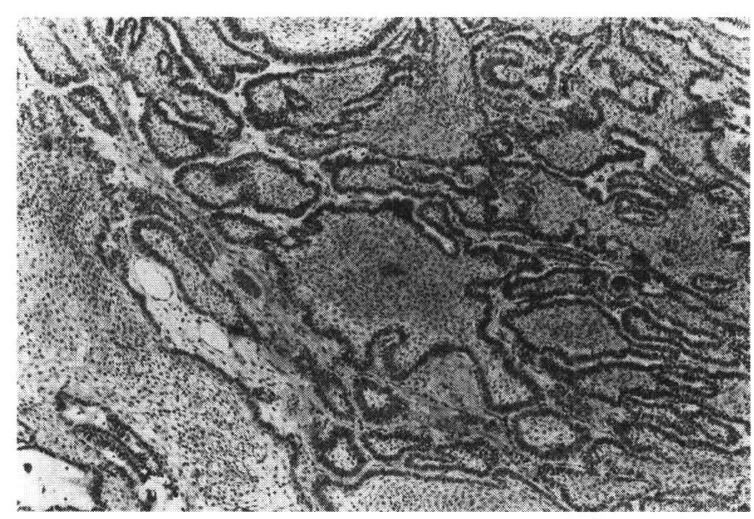

Fig. 4 The excised tumor tissue demonstrating tubular or interdigitating cords of single layered columnar epithelial cells. These epithelial cells surrounded loose, spindle-shaped cells resembling stellate reticulum $(\mathrm{H} \& \mathrm{E}$; original magnification ; $\times 100)$.

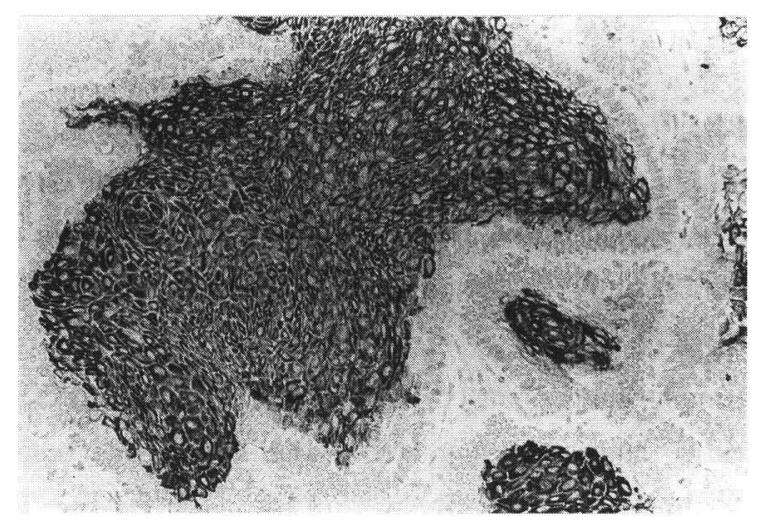

Fig. 5 The stellate cells of ameloblastoma showing positive immunoreaction for cytokeratin detected by KL-1 antibody (KL-1; original magnification ; $\times 200)$.

mors from other neoplasms such as squamous cell carcinoma, basal cell carcinoma, and small salivary gland tumor by radiography alone ${ }^{1,6)}$. MR, however, seems useful for planning surgery because it shows good contrast between the tumor and adjacent soft tissue. Ameloblastomas have intermediate to low signal intensity on $\mathrm{T} 1$ weighed images and high signal intensity on T2weighed images $^{6)}$. In our case, MR showed a clear interface between the tumor and fluid collection in the ethmoid and frontal sinus, not distinguishable by CT.

The biopsy specimen showed cell nests or interlacing formation of epithelial cells. Histological findings for ameloblastomas such as loose angular cells resembling satellite reticulae, microcysts in the stroma, or single layers of tall columnar cells with nuclei at the pole opposite the basement membrane were not clearly detected. We 
believe that the biopsy, obliquely cut from the tumor surface, obscured detection. Immunohistochemical examination proved useful in differential diagnosis. Kato ${ }^{7)}$ reported that immunohistochemical examination using anticytokeratin antibody $\mathrm{KL}-1$ and antiepithelial antibody Ber-EP4 is useful for distinguishing ameloblastoma with basal cell carcinoma-like features from adamantinoid basal cell carcinoma. In our case, negative findings of $\mathrm{S}-$ 100 protein and actin suggested that the tumor was neither of salivary duct origin nor a neurinoma. KL-1 antibody showed positive immunoreaction quite similar to that of enamel pulp.

Ameloblastomas are generally benign but locally invasive. Ameloblastomas in the maxilla generally recur more often than those in the mandible ${ }^{5)}$, commending en-block excision or segmental resection. We extirpated the tumor instead attempting total maxillectomy because of the absence of visible invasion to the sinus mucosa and maxillary bone except for the medial wall. Total maxillectomy also prevents postoperative functional and causes cosmetic problems.

MR is not specific in detecting ameloblastomas but is useful in detecting tumor recurrence. On T2 images, ameloblastomas show high signal intensity, whereas postoperative fibrosis shows intermediate to low signal intensity ${ }^{8,9)}$. Although we continue careful long-term follow-up using MR imaging, neither local recurrence nor distant metastasis has been found in this case.

\section{Acknowledgments}

This article was presented in part at an oral presentation at the 41st Congress of Japanese Rhinologic Society (Sep. 2002, Hiroshima, Japan).

\section{References}

1) Iko BO, Myers EM, Ogan O, et al: Ameloblastomas of the jaws: radiological diagnosis and follow-up. Br J Oral Maxillofac Surg 23 : 333-340,
1985.

2 ) Sirichitra V, Dhiravarangkura P, Hansasuta C: Diagnosis and treatment of ameloblastoma in the School of Dentistry, Chula-longkorn University. F Dent Assoc Thai 28 : 273-310, 1978.

3 ) Wu PC, Chan KW : A Survey of tumors of the jawbones in Hong Kong Chinise : 1963-1982. $\mathrm{Br} \mathrm{J}$ Oral Maxillofac Surg 23 : 92-102, 1985.

4 ) Small AI, Waldron CA : Ameloblastomas of the jaws. Oral Surg 8: 281-296, 1955.

5 ) Reichart PA, Philipsen HP, Sonner S: Ameloblastoma: Biological profile of 3677 cases. Oral Oncol, Eur J Cancer 31B : 86-99, 1995.

6 ) Heffez L, Mahmood FM, Vaiana J : The role of magnetic resonance imaging in the diagnosis and management of ameloblastoma. Oral Surg $65: 2^{-}$ 12, 1988 .

7 ) Kato N, Endo Y, Tamura G, et al : Ameloblastoma with basal cell carcinoma-like feature emerging as a nasal polyp. Pathology Int 49: 747-751, 1999.

8 ) Minami M, Kaneda $T$, Yamamoto $H$, et al : Ameloblastoma in the maxillomandibular region : MR imaging. Radiology 184 : 389-393, 1992.

9 ) Kawai T, Murakami S, Kishino M, et al: Diagnostic imaging in two cases of recurrent maxillary ameloblastoma : comparative evaluation of plain radiographs, CT and MR images. Brit J Oral Maxillofacial Surgery 36 : 304-310, 1998.

（2004年 1 月 22 日受稿， 2004年 6 月 11 日受理）

別刷請求先 : Yukie Yamamura, M. D.

Department of Otolaryngology, School of Medicine, Tokyo Women's Medical University

8-1, Kawada-cho, Shinjuku-ku, Tokyo 162-8666,

Japan

Tel : 03-3353-8111

Fax : 03-5269-7351 